\title{
Electroencephalography, Magnetic Resonance Imaging and Pathology in Patients Treated Surgically for Temporal Lobe Epilepsy
}

\author{
William Feindel, Yvon Robitaille, Donnatella Tampieri, \\ Lutgart Goossens, Maria Li and Denis Melançon
}

\begin{abstract}
In a consecutive series of 40 patients selected by EEG studies for surgical treatment of temporal lobe seizures, magnetic resonance imaging showed structural lesions in $25 \%$ and signal abnormalities, usually in the mesial temporal region, in another 35\%. Pathological changes included structural lesions in over 30\% of patients and sclerosis of the amygdala in almost half of the series. These findings further substantiate the implication of the amygdala in the pathogenesis of temporal lobe seizures with automatism and amnesia.
\end{abstract}

RÉSUMÉ: EEG, MRI et anatomo-pathologie chez les patients traités chirurgicalement pour une épilepsie temporale. Dans une série de 40 patients consécutifs, tous candidats (selon les données électroencéphalographiques) au traitement chirurgical de crises épileptiques provenant du lobe temporal, les études d'imagerie par résonance magnétique ont démontré des lésions structurales dans $25 \%$ des cas et des anomalies de signal, habituellement dans les régions mésiotemporales, chez un autre $35 \%$ des cas. L'étude pathologique des spécimens a révélé des lésions structurales dans plus de $30 \%$ des cas et une sclérose de l'amygdale dans presque la moitié des cas. Ces résultats suggèrent l'implication de l'amygdale dans la pathogenèse des crises d'origine temporale accompagnées d'automatismes et d'amnésie.

Can. J. Neurol. Sci. 1991; 18: 577-579

In previous reports, we have emphasized the implication of the amygdala in temporal lobe seizures characterized by automatism and amnesia. ${ }^{1-3}$ In a series of patients treated surgically for seizures of this type, the frequent detection of structural lesions in the mesial temporal lobe by magnetic resonance imaging has been catalogued.4-7 Two main varieties of lesions have been demonstrated. The first includes benign tumors, such as hamartomas, gangliogliomas and low grade astrocytomas as well as venous angiomas, heterotopia or dysplasia. The presence of these in association with temporal lobe epilepsy has been recognized by earlier reports where a surgical excision of epileptogenic tissue was carried out for treatment of the seizures. 2,8

The second class of abnormality demonstrated by MRI includes an increased signal intensity that we have reported earlier as being related to pathological changes in the amygdala and hippocampus. 6 This can be described as a sclerosis which involves astrocytic gliosis and neuronal cell loss. ${ }^{7}$ The identification of these focal pathological changes in the mesial temporal region and especially in the amygdala substantiates the viewpoint that temporal lobe seizures are often generated by epileptic discharge beginning in the amygdala. 3,9

To confirm and extend our earlier reports, we examined a series of forty-one consecutive patients, all treated surgically by one of us (WF) for temporal lobe epilepsy of the type which we have preferred to call amygdaloid seizures. These patients were all examined by MRI, as well as the usual localization studies by EEG and electrocorticography for determining the site of the epileptic abnormality. Because of the sparcity of pathological studies in the literature on the amygdala in such patients, a special effort was made to secure as much of the amygdala as possible by microdissection in order to examine it pathologically.

\section{Materials and Methods}

Consecutive cases selected for operation after appropriate investigations for localization of seizure activity and operated upon by a surgical team headed by WF were reviewed for analysis. Certain cases where data for a complete study were lacking were deleted as non-contributory to the study. The pathological material and the MRI films were reviewed separately by independent observers, neither of whom was aware of the specific EEG or surgical findings until these studies were completed.

The patients were operated upon between March 1985 and August 1988. Post-operative follow-up studies of this series will be reported elsewhere. In studies of earlier cases treated surgically in the same manner, with an anterior temporal cortisecto-

From the McConnell Brain Imaging Center, Montreal Neurological Institute and Hospital, Department of Neurology and Neurosurgery, McGill University, Montreal

Reprint requests to: W. Feindel, Montreal Neurological Institute and Hospital, Department of Neurology and Neurosurgery, Suite 110,3801 University Street, Montreal, Quebec, Canada H3A 2B4 
my and radical removal of the amygdala, the results for control of seizures were as satisfactory as in cases where excision included in addition a major portion of the hippocampus and hippocampal gyrus. ${ }^{10-12}$ These present findings, therefore, further substantiate the role of the amygdala in temporal lobe seizures by demonstrating the high incidence of abnormalities demonstrable by adequate magnetic resonance imaging (MRI) studies and surgical pathology where the amygdala is resected intact for microscopic examination.

MRI was made usually in three planes, coronal, axial and sagittal. Most cases were examined both by short and long TR, on sections $0.5 \mathrm{~cm}$ thick that covered the entire brain. Cases were examined in a Philips Gyro Scan, most taken at $0.5 \mathrm{~T}$ and the more recent cases at $1.5 \mathrm{~T}$.

EEG studies included the standard 20-20 electrode placement and sphenoidal electrodes with repeated studies and continuous monitoring for recording both interictal abnormality and ictal onset.

At operation, corticography was made before and after the excision, covering temporal, frontal and parietal cortex and, in most cases, with stimulation and recording by a depth electrode within the amygdala.

\section{Pathological Findings}

Surgical tissue was recovered from the temporal cortex and the amygdala which, instead of being removed by the usual suction technique, was dissected in one to three portions and submitted for neuropathological examination. When MRI displayed small focal lesions in the mesial temporal region, the tissue in that location was also carefully resected by the surgeon to retain it for microscopic examination.

In the anterior temporal cortex and amygdala which were submitted for pathological examination, there were 10 structural lesions, comprising 7 low-grade tumors (Figure 1) and 3 cavemous angiomas. Five additional cases showed mixed pathological changes including, heterotopia, microdysgenesis and hemangioma. Thus, of the thirty-eight cases that had satisfactory

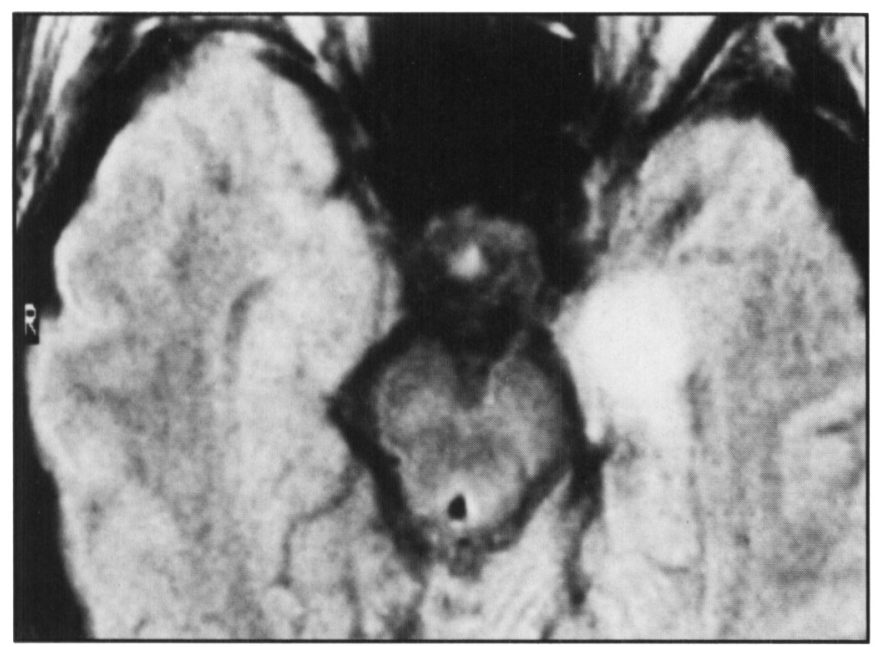

Figure I - MRI showing benign tumor (subependymoma) in the amygdala and anterior hippocampus, associated with temporal lobe seizures for 30 years. tissue for pathological examination, 15 had evident focal abnormality in the amygdaloid region.

In 26 patients there was sclerosis of the amygdala, with astrocytic gliosis and neuronal loss (Figures 2 and 3). This was of a mild degree in seven patients, moderate in thirteen patients and severe in six patients. Moreover, neuronal loss and gliosis were identified in the specimens of anterolateral temporal cortex

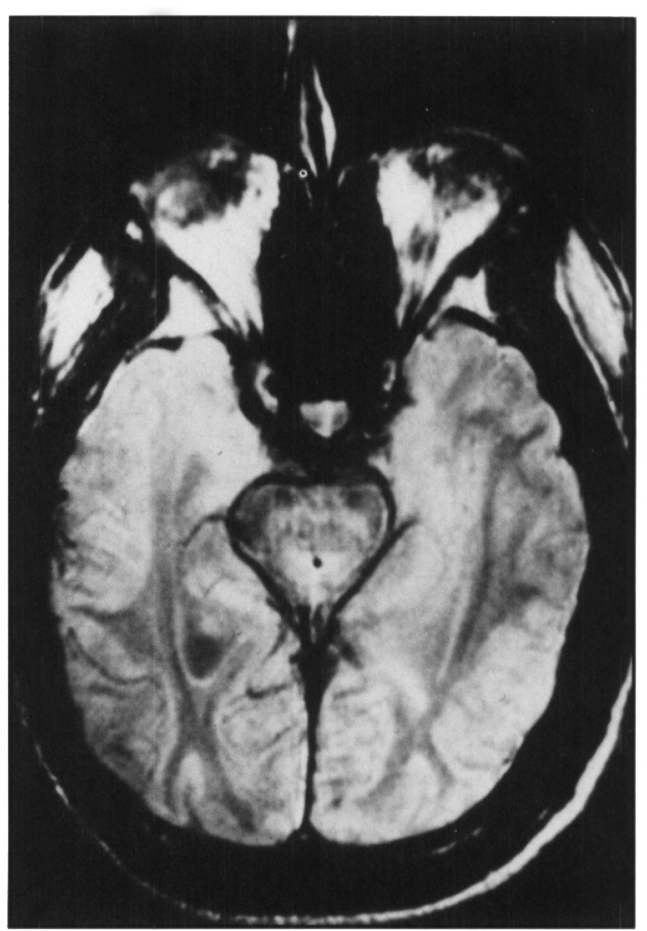

Figure 2 - Atrophy and increased signal from the temporal lobe (on left in figure) indicating mesial sclerosis.

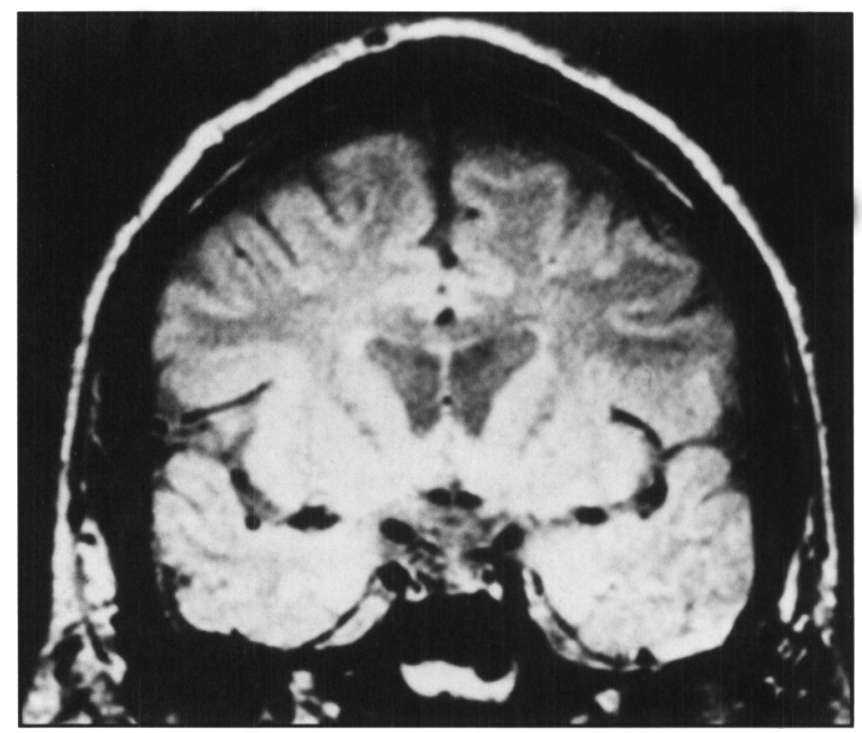

Figure 3 - Another example seen in the coronal phase of temporal lobe atrophy. 
submitted for examination, of a mild degree in twelve patients, moderate in four and severe in six, for a total of twenty-two.

Thus, in over half of the 41 patients who had adequate pathological examination there was either moderate to severe sclerosis in the amygdala or a structural lesion in the periamygdaloid region.

\section{MRI FINDINGS}

Of forty-one patients, the MRI examination was considered incomplete or inadequate in four and negative in six. In eleven cases, a structural lesion was demonstrated by MRI, including small tumors, cavernous angiomas and one arachnoid cyst. In the remaining fourteen cases, or one-third of the total there was judged to be an abnormal increase in signal in the antero-mesial temporal region. In addition, evidence of atrophy or asymmetry of the temporal lobes was demonstrated on MRI in nineteen cases.

\section{Discussion}

These results clearly indicate an incidence of structural abnormalities of over $25 \%$ demonstrable by MRI in the mesial temporal region and maximally in the region of the amygdala. An additional half of the patients showed evidence of abnormal signals. The total abnormalities detected on MRI thus came to almost $60 \%$ in these patients who were selected on the basis of EEG studies for surgical treatment of temporal lobe seizures.

Selective pathological examination of the amygdala, here reported for the first time in a consecutive series of patients undergoing surgical treatment, confirmed the presence of structural lesions in the amygdala and surrounding area of the mesial temporal region. In addition, careful examination of the amygdala itself showed the presence of significant sclerosis with astrocytic gliosis and neuronal loss in about half of the series.

Further studies on these data are now underway to determine the case correlation of the results from MRI, pathology, EEG and ECG, neuropsychology, with follow-up on control of seizures.

\section{Conclusion}

In a series of forty patients who were selected by EEG studies for surgical treatment of temporal lobe seizures and especially amygdaloid seizures, the results of MRI and pathological examinations are reported.
MRI showed structural lesions in $25 \%$ of the patients and abnormal signals in the mesial temporal region, usually maximal in the amygdala, in an additional $33 \%$ of the series.

The surgical tissue removed showed structural lesions in over one-third of the cases examined pathologically. In almost half of the cases moderate to severe sclerosis in the resected amygdala was demonstrated. In addition, in ten cases there was moderate to severe sclerosis found in the anterolateral temporal cortex.

These MRI and pathological findings substantiate previous evidence that the amygdala plays a critical role in the pathogenesis of temporal lobe seizures, especially amygdaloid seizures characterized by automatism and amnesia.

\section{REFERENCES}

1. Feindel W, Penfield W. Localization of discharge in temporal lobe automatism. Arch Neurol Psychiatry (Chic) 1954; 72: 605-630.

2. Feindel $W$. Temporal lobe seizures. In: Magnus $O$, Lorentz de Haas AM, eds. Handbook of Clinical Neurology. Amsterdam: NorthHolland Publishing, 1974; 87-106.

3. Feindel W. Amygdaloid seizures with automatism and amnesia: Centenary of a concept - from Hughlings-Jackson to MRI. Neuro-Image 1988; 5: 5-8.

4. McLachlan RS, Nicholson RL, Black S, et al. Nuclear magnetic resonance imaging, a new approach to the investigation of refractory temporal lobe epilepsy. Epilepsia 1985; 26: 555-562.

5. Sperling MR, Wilson G, Engel J, et al. Magnetic resonance imaging in intractable partial epilepsy: correlative studies. Ann Neurol 1986; 20: 57-62.

6. Kuzniecky R, de la Sayette V, Ethier, R, et al. Magnetic resonance imaging in temporal lobe epilepsy: pathological correlation. Ann Neurol 1987; 22: 341-347.

7. Feindel W, Robitaille Y, Ethier R, et al. Role of the amygdala in the surgery of temporal seizures: further evidence from magnetic resonance imaging and surgical pathology. Presented at the American Association of Neurological Surgeons. April 1988.

8. Penfield W, Flanigan H. Surgical therapy of temporal lobe seizures. Arch Neurol Psychiatry (Chic) 1950; 64: 491-500.

9. Feindel W, Robitaille Y. Temporal lobe seizures for 30 years: excision of amygdaloid sub-ependymoma detected by MRI. NeuroImage 1989; 6: 5-8.

10. Rasmussen T, Feindel W. Temporal lobectomy with major hippocampectomy: review of 100 cases. (this supplement)

11. Feindel W, Rasmussen T. Temporal lobectomy with amygdalectomy and minimal hippocampal resection: review of 100 cases. (this supplement)

12. Leonard G. Temporal lobe surgery for epilepsy: neuropsychological variables related to surgical outcome.(this supplement) 